\title{
Targeted treatment of mutated EGFR-expressing non-small-cell lung cancer: focus on erlotinib with companion diagnostics
}

This article was published in the following Dove Press journal:

Lung Cancer: Targets and Therapy

13 November 2014

Number of times this article has been viewed

\author{
Niki Karachaliou' \\ Rafael Rosell ${ }^{2}$ \\ 'Translational Research Unit, \\ Dr Rosell Oncology Institute, Quirón \\ Dexeus University Hospital, ${ }^{2}$ Cancer \\ Biology and Precision Medicine \\ Program, Catalan Institute of \\ Oncology, Hospital Germans Trias i \\ Pujol, Barcelona, Spain
}

\begin{abstract}
Deeper understanding of the pathobiology of non-small-cell lung cancer (NSCLC) has led to the development of small molecules that target genetic mutations known to play critical roles in the progression to metastatic disease. The discovery of epidermal growth factor receptor $(E G F R)$ mutations in 15\%-20\% of lung adenocarcinomas and the associated response to EGFR tyrosine kinase inhibitors have provided a successful avenue of attack in late-stage adenocarcinomas. Use of the EGFR tyrosine kinase inhibitors gefitinib, erlotinib, and afatinib is limited to patients who have adenocarcinomas with known activating EGFR mutations. However, the EGFR mutation testing landscape is varied and includes many screening and targeted methods, each with its own benefits and limitations. These tests can simplify the drug discovery process, make clinical trials more efficient and informative, and individualize cancer therapy. In practice, the choice of method should be determined by the nature of the sample to be tested, the testing laboratory's expertise and access to equipment, and whether the detection of only known activating EGFR mutations, or of all possible mutations, is required. Development of companion diagnostic tests for this identification is advancing; nevertheless, the use of such tests merits greater attention.
\end{abstract}

Keywords: lung adenocarcinoma, EGFR mutations, companion diagnostics

\section{Introduction}

Lung cancer is the leading cause of cancer-related death in the United States and it accounts for more than 1 million deaths worldwide each year. ${ }^{1}$ In recent years, the diagnosis and treatment of patients with advanced lung cancer have undergone transformational changes. The current paradigm for prescribing novel targeted therapies is based on selecting patients according to the presence of specific oncogenic abnormalities in the tumor. ${ }^{2}$ The first of such abnormalities discovered in lung cancer were epidermal growth factor receptor $(E G F R)$ kinase domain mutations; tumors with these mutations were found to be sensitive to EGFR tyrosine kinase inhibitors (TKIs). ${ }^{3}$

Aside from the primary non-small-cell lung cancer (NSCLC) driver oncogenes (KRAS, EGFR, and $A L K$, which are mutated in more than $5 \%$ of NSCLC), several known or potential lung cancer oncogenes are mutated in $<5 \%$ of cases. However, because lung cancer is a major lethal disease, detection of a mutation that occurs even at low rates could represent many affected patients and thus should not be ignored especially mutations that are actionable for developing new targeted therapies. ${ }^{4} \mathrm{We}$ review the literature on the state-of-the-art treatment of EGFR-mutant NSCLC patients,
Correspondence: Rafael Rosell Catalan Institute of Oncology, Hospital Germans Trias i Pujol, Ctra Canyet s/n, Badalona, Barcelona 08916, Spain Email rrosell@iconcologia.net 
highlighting the available methods to identify those most likely to benefit from treatment with EGFR-targeted therapy.

\section{Targeted treatment of mutated EGFR-expressing NSCLC First-generation EGFR TKIs}

Causative EGFR mutations, either a deletion in exon 19 or an amino acid substitution at codon 858 in exon 21 (L858R), ${ }^{5,6}$ were present in $16.6 \%$ of Spanish NSCLC patients, and more frequently in adenocarcinomas in females (30\%) and never-smokers (37.7\%). ${ }^{7}$ Gefitinib and erlotinib are firstgeneration reversible EGFR TKIs approved for treatment of EGFR-mutant NSCLC. Both selectively bind to the adenosine triphosphate-binding site of the receptor. A third firstgeneration inhibitor, icotinib, is currently undergoing clinical trials, and previous studies have demonstrated its decreased toxicity profile and similar efficacy to gefitinib. ${ }^{8,9}$

Gefitinib received accelerated approval in 2003 for patients with advanced NSCLC based on studies that demonstrated rare but dramatic responses in unselected patients. ${ }^{10,11}$ However, in 2005, given the lack of a significant survival benefit compared to best supportive care, US Food and Drug Administration (FDA) approval was withdrawn for all patients except those who had previously benefited from the drug. ${ }^{12}$

In 2009, NSCLC patients receiving gefitinib as a first-line therapy in the IPASS trial $^{13}$ had a longer progression-free survival (PFS) compared to those receiving carboplatin plus paclitaxel. When the impact of therapy was based on patients' genotype, the PFS for those with EGFR-mutant tumors was significantly longer among patients who received gefitinib than those treated with chemotherapy $(9.5$ versus 6.3 months, hazard ratio $[\mathrm{HR}]=0.48 ; 95 \%$ confidence interval $[\mathrm{CI}]=0.36-0.64 ; P<0.001) .{ }^{13}$ However, the median overall survival (OS) was similar in both study arms. ${ }^{13}$

One year later, two subsequent Phase III trials conducted in Asian populations of EGFR-mutant positive patients confirmed the findings from the IPASS study. The North-East Japan Study Group trial ${ }^{14}$ demonstrated a PFS of 10.4 months with first-line gefitinib compared to 5.5 months with chemotherapy $(\mathrm{HR}=0.30 ; 95 \% \mathrm{CI}=0.22-0.41 ; P<0.001)$, although the WJTOG3405 study ${ }^{15}$ found a PFS of 9.2 months with gefitinib compared to 6.3 months with chemotherapy (HR $=0.489 ; 95 \% \mathrm{CI}=0.336-0.710$; log-rank, $P<0.0001)$.

The OPTIMAL ${ }^{16}$ and EURTAC trials ${ }^{3}$ were published in 2011 and 2012, respectively, and they confirmed a PFS benefit for $E G F R$-mutant NSCLC treated with erlotinib when compared to standard chemotherapy in first-line therapy. TKI-sensitizing mutations (exon 19 deletion or exon 21 L858R mutation) were mandatory for enrollment in these studies. The OPTIMAL study ${ }^{16}$ demonstrated a PFS of 13.1 months with first-line erlotinib compared to 4.6 months with gemcitabine plus carboplatin $(\mathrm{HR}=0.16$; 95\% CI $=0.66-0.99 ; P=0.037$ ) in a Chinese population. The EURTAC study ${ }^{3}$ compared standard platinum doublet chemotherapy to erlotinib in the first-line setting for $E G F R$ mutant NSCLC in a European population. Again, a significant improvement in PFS in favor of the erlotinib arm over standard chemotherapy (PFS 9.7 months versus 5.2 months; HR $=0.37 ; 95 \% \mathrm{CI}=0.25-0.54 ; P>0.0001)$ was observed. Based on these results, in May 2013, erlotinib was approved by the US FDA for the first-line treatment of patients with NSCLC whose tumors harbor causative EGFR mutations.

Although EGFR TKIs, such as erlotinib or gefitinib, are standard treatment for patients with EGFR-mutant NSCLC, ${ }^{17}$ the median PFS still does not exceed 10 months ${ }^{3}$ and no combination therapies have yet been incorporated into clinical practice to overcome potential mechanisms of failure to single EGFR TKIs. Among patients progressing on first-generation EGFR TKIs, 50\% have tumors with a secondary T790M mutation. ${ }^{18}$ The emergence of the T790M $E G F R$ gatekeeper mutation and upregulation of downstream signaling by $M E T$ amplification have been described as the two main mechanisms responsible for acquired resistance. ${ }^{19}$ However, a Phase III trial ${ }^{20}$ enrolling only patients with MET-positive tumors was stopped in early March 2014 due to futility; there was no evidence to suggest a positive effect of the addition of onartuzumab to erlotinib.

In a recent report, the combination of bevacizumab and erlotinib in the first-line setting was superior to erlotinib alone in patients with EGFR-mutant NSCLC. Remarkably, the combination had a median PFS of 16.0 months versus 9.7 months for erlotinib alone (HR $=0.54 ; 95 \%$ $\mathrm{CI}=0.36-0.79 ; P=0.0015) .{ }^{21}$ Other studies, such as BELIEF $^{17}$ (NCT01562028), and an ongoing in US trial (NCT01532089), are being carried out with the combination of erlotinib and bevacizumab with the primary objective of clarifying the role of this combination in the subgroup of $E G F R$-mutant NSCLC patients who also harbor the EGFR T790M mutation. ${ }^{22}$ These studies pave the way to move from single EGFR TKIs to combination therapy to improve outcomes in EGFR-mutant NSCLC. If the clinical benefit of the combination of EGFR TKIs with vascular endothelial growth factor (VEGF)-targeted therapies is further validated, additional research could be warranted to prevent the 
occurrence of possible novel mechanisms of resistance to VEGF-targeted therapies.

\section{Second- and third-generation EGFR TKIs}

Second-generation EGFR TKIs were developed to overcome resistance to first-generation inhibitors. Currently, there are two lead second-generation EGFR TKI candidates, afatinib and dacomitinib, which are active against EGFR mutations with acquired resistance to erlotinib or gefitinib. ${ }^{23}$ These drugs have the advantage of forming covalent, irreversible bonds with the target, which increases their effectiveness through the prolonged inhibition of EGFR signaling. It is hypothesized that prolonged and irreversible inhibition of the receptor has the potential for further improvement in response to treatment over first-generation TKIs.

Afatinib was recently approved for the first-line treatment of EGFR-mutant NSCLC in the US and for treatment of EGFR-mutant TKI-naïve patients in Europe and Japan. The approval was based on data from the pivotal LUX-Lung 3 trial, ${ }^{24}$ which compared afatinib to chemotherapy with pemetrexed plus cisplatin. The trial showed that patients on afatinib had a PFS of 13.6 months versus 6.9 months for chemotherapy $(\mathrm{HR}=0.47 ; 95 \% \mathrm{CI}=0.34-0.65 ; P=0.001) .{ }^{24}$ In the LUX-Lung 6 trial, ${ }^{25}$ afatinib was compared to gemcitabine plus cisplatin for patients with $E G F R$ mutations. PFS with afatinib was 11.0 months versus 5.6 months with chemotherapy $(\mathrm{HR}=0.28 ; 95 \% \mathrm{CI}=0.20-0.39 ; P<0.0001) .{ }^{2.5}$ Notably, a recent pooled analysis of these two trials revealed an OS benefit for the afatinib arm (median OS: 27.3 months versus 24.3 months; $\mathrm{HR}=0.81 ; 95 \% \mathrm{CI}=0.66-0.99 ; P=0.037$ ) with the majority of benefit observed for patients with exon 19 deletions (median OS: 31.7 months versus 20.7 months; $\mathrm{HR}=0.59 ; 95 \% \mathrm{CI}=0.45-0.77 ; P<0.001) .{ }^{26}$ Of note, some patients with uncommon de novo T790M and exon 20 insertions appeared to derive a benefit from afatinib. ${ }^{27}$

The second-generation EGFR TKI, dacomitinib, is a pan-human epidermal growth factor receptor (HER) inhibitor that irreversibly binds to EGFR, HER2, and HER4 tyrosine kinases..$^{28}$ Preclinical studies have demonstrated antitumor activity in NSCLC cell lines with sensitive and resistant EGFR mutations..$^{28}$ A Phase I dose-escalation study ${ }^{29}$ of dacomitinib in 121 patients with advanced solid tumors (57 of whom had NSCLC) established the maximum tolerated dose as $45 \mathrm{mg}$ /day, with dose-limiting toxicities of stomatitis and skin toxicities. Subsequent randomized studies comparing dacomitinib with erlotinib in unselected NSCLC populations of previously treated NSCLC patients failed to demonstrate significant improvement in outcomes..$^{30,31}$ However, the role of dacomitinib as a first-line therapy in patients with activating EGFR mutations has not yet been explored.

We recently reported the possible causes of resistance to EGFR TKIs in EGFR-mutant NSCLC patients: the high coexistence of the pretreatment somatic T790M mutation with a clear impact on PFS; and the role of BIM messenger RNA expression as an independent prognostic marker. ${ }^{22}$ Pretreatment T790M can be detected in more than $60 \%$ of patients. ${ }^{22}$ In fact, using a peptide nucleic acid (PNA) clamp polymerase chain reaction (PCR) assay, pretreatment T790M mutations were detected in $65.26 \%$ of patients. ${ }^{22}$ These results reinforce the need for second- and third-generation EGFR TKIs, without forgetting the existing data that suggest the use of erlotinib or gefitinib beyond progression, with added chemotherapy, radiotherapy, or best supportive care as a way to improve survival. ${ }^{32}$

CO-1686 is a novel covalent inhibitor that irreversibly and selectively targets both the initial activating EGFR mutations and the T790M secondary acquired resistance mutation..$^{33}$ To investigate its use as a single agent, CO-1686 is being evaluated in a Phase I/II trial ${ }^{34}$ in EGFR-mutant NSCLC patients previously treated with first-line gefitinib or erlotinib (NCT01526928). In the Phase I study, and based on early findings from the ongoing Phase II trial, the agent yielded a $58 \%$ overall response rate across all dose levels in trial participants with biopsy-confirmed EGFR T790M mutations. Additionally, the compound did not cause the rash and diarrhea commonly associated with earlier generations of EGFR inhibitors. ${ }^{35}$

AZD9291 showed high activity in preclinical studies and was well tolerated in animal models. Xenograft studies identified a breakdown metabolite of AZD9291 called AZ5104 that is approximately five times as potent as AZD9291 itself. ${ }^{36}$ In the Phase I study ${ }^{37}$ of AZD9291 in EGFR-mutant patients resistant to standard EGFR TKIs, $50 \%$ of patients experienced tumor shrinkage and the drug worked particularly well in patients with the T790M mutation.

\section{Companion diagnostics}

There is a growing trend toward the extensive molecular characterization of tumors to select the most appropriate therapy. The benefits of EGFR TKI treatment can be maximized if used with clinically validated and accurate companion diagnostics. Robust and accurate assays with rapid turnaround time are preferred. Important factors in assay performance include analytic standardization, validation of reagents and methodology, laboratory experience, and involvement of the pathologist. However, recent 
quality assurance studies to ascertain the mutation status of a standard panel of tumors have shown that different clinical laboratories do not correctly identify the mutation status of $100 \%$ of the panel members, even when using identical or similar testing methodologies..$^{38,39}$

In July 2011, the US FDA released a draft guidance to explain its policy requiring the review and regulatory approval of companion diagnostics as essential tools to guide the use of corresponding therapies. ${ }^{40}$ The guidance, aimed at stimulating early collaborations between drug and device makers, clarified the US FDA's definition of a companion diagnostic; it recommended the early interaction between drug and device manufacturers and the US FDA, and it identified instances in which the US FDA may approve a targeted treatment in the absence of a cleared or approved companion diagnostic. For instance, the US FDA may decide to approve a drug even though the indicated in vitro companion diagnostic device is not US FDA-approved, particularly in diseases like cancer, for which no satisfactory alternative treatments exist. In these patients, the benefits of using the drug with an unapproved or uncleared in vitro companion diagnostic are so clear as to outweigh the risks associated with the lack of an approved in vitro companion diagnostic device.

DNA mutational analysis is the preferred method to assess $E G F R$ status. A multitude of techniques have been developed as potential alternatives to the historical standard for $E G F R$ mutation testing - specifically, direct DNA sequencing. Direct sequencing has low sensitivity, can be complex and time consuming, and is not standardized in terms of laboratory practice. ${ }^{41}$ However, these novel techniques have varying sensitivities to detect known and de novo mutations, with differing instruments reagents, assay run times, and costs. ${ }^{42}$ The PNA-PCR clamp assay is one method capable of detecting EGFR mutations in a background of wild-type $E G F R^{3}{ }^{3}$ This method employs fluorescent primers with preferred amplification of the mutant sequence, which is then detected by locked nucleic acids to increase specificity. The sensitivity and specificity of the PNA-PCR clamp method are $97 \%$ and $100 \%$, respectively. ${ }^{43}$

Many commercial EGFR mutation detection kits are available, including those from Genzyme Corporation (Cambridge, MA, USA) and Qiagen NV (Venlo, The Netherlands). The Roche cobas ${ }^{\circledR} E G F R$ Mutation Test (a real-time, PCR-based diagnostic test) (Hoffman-La Roche Ltd, Basel, Switzerland) is CE-marked and identifies 41 mutations across exons 18, 19,20 , and 21 . In parallel with the approval of erlotinib as a first-line treatment for patients who harbor the $E G F R$ mutation, the US FDA announced the approval of the cobas
EGFR Mutation Test as a companion diagnostic for erlotinib, making it the first US FDA-approved companion diagnostic able to detect $E G F R$ mutations. The safety and effectiveness of the cobas EGFR Mutation Test was established through the retrospective analysis of a clinical validation study in a subset of lung cancer specimens from patients screened in the EURTAC trial. ${ }^{44}$ The test demonstrated improved sample workflow relative to the laboratory-developed tests used in the trial, enabling EGFR mutation screening in a single assay with a 1-day turnaround time. The EGFR PCR test was highly concordant $(>96 \%)$ with the laboratory-developed tests to select patients for the EURTAC trial, ${ }^{44}$ and it showed superior sensitivity and specificity when compared with conventional Sanger sequencing.

In July 2013, the US FDA approval of the Scorpion Amplified Refractory Mutation System therascreen ${ }^{\circledR} E G F R$ Rotor-Gene $^{\circledR}$ Q PCR kit (therascreen EGFR assay; Qiagen NV) was followed by the US FDA priority review of afatinib. Recently, a high concordance rate $(98.0 \%)$ of the cobas $E G F R$ assay with the therascreen EGFR assay has been demonstrated. ${ }^{45}$ In the study from Kimura et $a l,{ }^{45}$ both assays proved to be simple, validated methods for detecting the most common, clinically significant EGFR mutations, and they proved to be helpful for appropriate treatment guidance for NSCLC patients. However, the cobas EGFR assay has two advantages over the therascreen assay: first, it takes only 8 hours to go from the tumor specimen to the results, and patients can begin the most appropriate treatment within a shorter time; second, only a very small amount of DNA is required to detect tumor mutation status. ${ }^{45}$ In Table 1, we have summarized the main techniques for EGFR mutation testing.

Testing of tumor tissue remains the recommended method for detecting the presence of causative EGFR mutations. However, little tumor tissue may be obtained by biopsy, especially in advanced NSCLC, raising the question of whether circulating tumor (ct)DNA may be used as a surrogate liquid biopsy for the noninvasive assessment of EGFR mutations. The first blood-based $E G F R$ mutation analysis was performed in serum obtained from Japanese patients with NSCLC before gefitinib treatment, using Scorpion Amplified Refractory Mutation System technology. EGFR mutation status in tumor tissue was consistent with that in serum in $72.7 \%$ of the paired samples. ${ }^{46}$ This finding indicated the feasibility of using serum DNA for the detection of EGFR mutations, and since then, several studies have assessed EGFR mutations in serum or plasma using different methods. ${ }^{47-53}$ The rate of detection of EGFR mutations in ctDNA varies according to the method used. ${ }^{46,48,49,52,54-62}$ A large meta-analysis of 1,591 patients tested by different 
Table I Primary techniques for EGFR mutation testing

Direct DNA sequencing

Historical standard for EGFR mutation testing

PCR assays

PNA-PCR clamp assay

Cobas $^{\circledR}$ EGFR Test; first FDA-approved companion diagnostic

Therascreen ${ }^{\circledR}$ EGFR assay; FDA-approved companion diagnostic
Low sensitivity, complex, time-consuming, not standardized in terms of laboratory practice

Simple, validated methods for detecting the most common, clinically significant EGFR mutations. Superior sensitivity and specificity compared with conventional Sanger sequencing. Not time consuming, require small amount of DNA

Abbreviations: PCR, polymerase chain reaction; PNA, peptide nucleic acid; US FDA, United States Food and Drug Administration.

methods reported a pooled sensitivity rate of $64.5 \%$, but it was found that the results were influenced by the test method $(P=0.04) .{ }^{63}$ Therefore, the sensitivity of $E G F R$ mutation testing in ctDNA still requires further improvement.

\section{Conclusion}

Personalized therapy for NSCLC patients should include a genetic assessment of EGFR mutational status for individual patients. Erlotinib, gefitinib, and afatinib are currently available as treatments for patients with advanced NSCLC who harbor EGFR mutations. Until now, no head-to-head trials between these TKIs in populations with the EGFR mutation have been reported, which provides room for indirect and integrated comparisons. In addition, the appropriate role of routine $E G F R$ mutation analysis in the treatment of patients with NSCLC is constantly evolving. These issues should form the basis for new prospective clinical studies investigating new standards of care to determine which of the different EGFR TKIs is best, and to ensure adequate documentation of the patient's $E G F R$ mutation status in the preclinical setting, during the treatment, and during follow-up.

\section{Disclosure}

The authors report no conflicts of interest in this work.

\section{References}

1. Siegel R, Ma J, Zou Z, Jemal A. Cancer statistics, 2014. CA Cancer J Clin. 2014;64(1):9-29.

2. Karachaliou N, Rosell R, Morales-Espinosa D, Viteri S. Systemic treatment in EGFR-ALK NSCLC patients: second line therapy and beyond. Expert Rev Anticancer Ther. 2014;14(7):807-815.

3. Rosell R, Carcereny E, Gervais R, et al; Spanish Lung Cancer Group in collaboration with Groupe Français de Pneumo-Cancérologie and Associazione Italiana Oncologia Toracica. Erlotinib versus standard chemotherapy as first-line treatment for European patients with advanced EGFR mutation-positive non-small-cell lung cancer (EURTAC): a multicentre, open-label, randomised phase 3 trial. Lancet Oncol. 2012;13(3):239-246.

4. Pao W, Hutchinson KE. Chipping away at the lung cancer genome. Nat Med. 2012;18(3):349-351.

5. Politi K, Zakowski MF, Fan PD, Schonfeld EA, Pao W, Varmus HE. Lung adenocarcinomas induced in mice by mutant EGF receptors found in human lung cancers respond to a tyrosine kinase inhibitor or to downregulation of the receptors. Genes Dev. 2006;20(11):1496-1510.
6. Ji H, Li D, Chen L, et al. The impact of human EGFR kinase domain mutations on lung tumorigenesis and in vivo sensitivity to EGFRtargeted therapies. Cancer Cell. 2006;9(6):485-495.

7. Rosell R, Moran T, Queralt C, et al; Spanish Lung Cancer Group. Screening for epidermal growth factor receptor mutations in lung cancer. N Engl J Med. 2009;361(10):958-967.

8. Gu A, Shi C, Xiong L, Chu T, Pei J, Han B. Efficacy and safety evaluation of icotinib in patients with advanced non-small cell lung cancer. Chin J Cancer Res. 2013;25(1):90-94.

9. Shi Y, Zhang L, Liu X, et al. Icotinib versus gefitinib in previously treated advanced non-small-cell lung cancer (ICOGEN): a randomised, double-blind phase 3 non-inferiority trial. Lancet Oncol. 2013;14(10):953-961.

10. Kris MG, Natale RB, Herbst RS, et al. Efficacy of gefitinib, an inhibitor of the epidermal growth factor receptor tyrosine kinase, in symptomatic patients with non-small cell lung cancer: a randomized trial. JAMA. 2003;290(16):2149-2158.

11. Fukuoka M, Yano S, Giaccone G, et al. Multi-institutional randomized phase II trial of gefitinib for previously treated patients with advanced non-small-cell lung cancer (The IDEAL 1 Trial) [corrected]. $J$ Clin Oncol. 2003;21(12):2237-2246.

12. Thatcher N, Chang A, Parikh P, et al. Gefitinib plus best supportive care in previously treated patients with refractory advanced nonsmall-cell lung cancer: results from a randomised, placebo-controlled, multicentre study (Iressa Survival Evaluation in Lung Cancer). Lancet. 2005;366(9496):1527-1537.

13. Mok TS, Wu YL, Thongprasert S, et al. Gefitinib or carboplatinpaclitaxel in pulmonary adenocarcinoma. NEngl J Med. 2009;361(10): 947-957.

14. Maemondo M, Inoue A, Kobayashi K, et al; North-East Japan Study Group. Gefitinib or chemotherapy for non-small-cell lung cancer with mutated EGFR. N Engl J Med. 2010;362(25):2380-2388.

15. Mitsudomi T, Morita S, Yatabe Y, et al; West Japan Oncology Group. Gefitinib versus cisplatin plus docetaxel in patients with non-smallcell lung cancer harbouring mutations of the epidermal growth factor receptor (WJTOG3405): an open label, randomised phase 3 trial. Lancet Oncol. 2010;11(2):121-128.

16. Zhou C, Wu YL, Chen G, et al. Erlotinib versus chemotherapy as first-line treatment for patients with advanced EGFR mutation-positive non-smallcell lung cancer (OPTIMAL, CTONG-0802): a multicentre, open-label, randomised, phase 3 study. Lancet Oncol. 2011;12(8):735-742.

17. Rosell R, Bivona TG, Karachaliou N. Genetics and biomarkers in personalisation of lung cancer treatment. Lancet. 2013;382(9893):720-731.

18. Lee CK, Brown C, Gralla RJ, et al. Impact of EGFR inhibitor in non-small cell lung cancer on progression-free and overall survival: a meta-analysis. J Natl Cancer Inst. 2013;105(9):595-605.

19. Sequist LV, Waltman BA, Dias-Santagata D, et al. Genotypic and histological evolution of lung cancers acquiring resistance to EGFR inhibitors. Sci Transl Med. 2011;3(75):75ra26.

20. Spigel DR, Edelman MJ, O’Byrne K, et al. Onartuzumab plus erlotinib versus erlotinib in previously treated stage IIIb or IV NSCLC: results from the pivotal phase III randomized, multicenter, placebo-controlled METLung (OAM4971g) global trial [abstract]. J Clin Oncol. 2014; 32 Suppl 5:abstract 8000. 
21. Seto T, Kato T, Nishio M, et al. Erlotinib alone or with bevacizumab as first-line therapy in patients with advanced non-squamous nonsmall-cell lung cancer harbouring EGFR mutations (JO25567): an open-label, randomised, multicentre, phase 2 study. Lancet Oncol. 2014;15(11):1236-1244.

22. Costa C, Molina MA, Drozdowskyj A, et al. The impact of EGFR T790M mutations and BIM mRNA expression on outcome in patients with EGFR-mutant NSCLC treated with erlotinib or chemotherapy in the randomized phase III EURTAC trial. Clin Cancer Res. 2014;20(7):2001-2010.

23. Ou S. Second-generation irreversible epidermal growth factor receptor (EGFR) tyrosine kinase inhibitors (TKIs): a better mousetrap? A review of the clinical evidence. Crit Rev Oncol Hematol. 2012;83(3): $407-421$.

24. Sequist LV, Yang JC, Yamamoto N, et al. Phase III study of afatinib or cisplatin plus pemetrexed in patients with metastatic lung adenocarcinoma with EGFR mutations. J Clin Oncol. 2013;31(27): 3327-3334.

25. Wu YL, Zhou C, Hu CP, et al. Afatinib versus cisplatin plus gemcitabine for first-line treatment of Asian patients with advanced non-small-cell lung cancer harbouring EGFR mutations (LUX-Lung 6): an open-label, randomised phase 3 trial. Lancet Oncol. 2014;15(2):213-222.

26. Chih-Hsin Yang J, Sequist LV, Schuler MH, et al. Overall survival (OS) in patients (pts) with advanced non-small cell lung cancer (NSLCL) harboring common (Del19/L858R) epidermal growth factor receptor mutations (EGFR mut): pooled analysis of two large open-label phase III studies (LUX-Lung 3 [LL3] and LUX-Lung 6 [LL6]) comparing afatinib with chemotherapy (CT) [abstract]. J Clin Oncol. 2014; 32 Suppl 5:abstract 8004.

27. Yang JC, Sequist LV, Geater S, et al. Activity of afatinib in uncommon epidermal growth factor receptor (EGFR) mutations: findings from three trials of afatinib in EGFR mutation-positive lung cancer. World Congress on Lung Cancer; October 27-31; 2013; Sydney, Australia.

28. Engelman JA, Zejnullahu K, Gale CM, et al. PF00299804, an irreversible pan-ERBB inhibitor, is effective in lung cancer models with EGFR and ERBB2 mutations that are resistant to gefitinib. Cancer Res. 2007; 67(24):11924-11932.

29. Jänne PA, Boss DS, Camidge DR, et al. Phase I dose-escalation study of the pan-HER inhibitor, PF299804, in patients with advanced malignant solid tumors. Clin Cancer Res. 2011;17(5):1131-1139.

30. Ramalingam SS, Blackhall F, Krzakowski M, et al. Randomized phase II study of dacomitinib (PF-00299804), an irreversible panhuman epidermal growth factor receptor inhibitor, versus erlotinib in patients with advanced non-small-cell lung cancer. J Clin Oncol. 2012; 30(27):3337-3344.

31. Ramalingam SS, Janne PA, Mok T, et al. Randomized, double-blinded study of dacomitinib, an irreversible pan-human epidermal growth factor receptor (HER) inhibitor, versus erlotinib for second-line/thirdline therapy of locally advanced/metastatic non-small cell lung cancer (ARCHER 1009) [abstract]. J Clin Oncol. 2014;32 Suppl 5:abstract 8018.

32. Faehling M, Eckert R, Kamp T, et al. EGFR-tyrosine kinase inhibitor treatment beyond progression in long-term Caucasian responders to erlotinib in advanced non-small cell lung cancer: a case-control study of overall survival. Lung Cancer. 2013;80(3):306-312.

33. $\mathrm{Mu} \mathrm{X}$, Lin $\mathrm{S}$, Yang $\mathrm{J}$, et al. TGF- $\beta$ signaling is often attenuated during hepatotumorigenesis, but is retained for the malignancy of hepatocellular carcinoma cells. PLoS One. 2013;8(5):e63436.

34. Berardi R, Santoni M, Morgese F, et al. Novel small molecule EGFR inhibitors as candidate drugs in non-small cell lung cancer. Onco Targets Ther. 2013;6:563-576.

35. Sequist LV, Soria JC, Shirish M, et al. First-in-human evaluation of CO-1686, an irreversible, highly selective tyrosine kinase inhibitor of mutations of EGFR (activating and T790M) [abstract]. J Clin Oncol. 2014;32 Suppl 5:abstract 8010 .

36. Targeting resistance in lung cancer. Cancer Discov. 2013;3(12):OF9.
37. Janne PA, Ramalingam SS, Chih-Hsing Yang J, et al. Clinical activity of the mutant-selective EGFR inhibitor AZD9291 in patients (pts) with EGFR inhibitor-resistant non-small cell lung cancer (NSCLC) [abstract]. J Clin Oncol. 2014;32 Suppl 5:abstract 8009.

38. Beau-Faller M, Degeorges A, Rolland E, et al. Cross-validation study for epidermal growth factor receptor and KRAS mutation detection in 74 blinded non-small cell lung carcinoma samples: a total of 5550 exons sequenced by 15 molecular French laboratories (evaluation of the EGFR mutation status for the administration of EGFR-TKIs in non-small cell lung carcinoma [ERMETIC] project - part 1). J Thorac Oncol. 2011;6(6):1006-1015.

39. Bellon E, Ligtenberg MJ, Tejpar S, et al. External quality assessment for KRAS testing is needed: setup of a European program and report of the first joined regional quality assessment rounds. Oncologist. 2011;16(4):467-478.

40. US Food and Drug Administration. In Vitro Companion Diagnostic Devices - Guidance for Industry and Food and Drug Administration Staff. Silver Spring, MD: US Food and Drug Administration; 2014.

41. Penzel R, Sers C, Chen Y, et al. EGFR mutation detection in NSCLC - assessment of diagnostic application and recommendations of the German Panel for Mutation Testing in NSCLC. Virchows Arch. 2011;458(1):95-98.

42. Nagai Y, Miyazawa H, Huqun, et al. Genetic heterogeneity of the epidermal growth factor receptor in non-small cell lung cancer cell lines revealed by a rapid and sensitive detection system, the peptide nucleic acid-locked nucleic acid PCR clamp. Cancer Res. 2005;65(16): 7276-7282.

43. Sutani A, Nagai Y, Udagawa K, et al. Gefitinib for non-small-cell lung cancer patients with epidermal growth factor receptor gene mutations screened by peptide nucleic acid-locked nucleic acid PCR clamp. Br J Cancer. 2006;95(11):1483-1489.

44. Benlloch S, Botero ML, Beltran-Alamillo J, et al. Clinical validation of a PCR assay for the detection of EGFR mutations in non-small-cell lung cancer: retrospective testing of specimens from the EURTAC trial. PLoS One. 2014;9(2):e89518.

45. Kimura H, Ohira T, Uchida O, et al. Analytical performance of the cobas EGFR mutation assay for Japanese non-small-cell lung cancer. Lung Cancer. 2014;83(3):329-333.

46. Kimura H, Kasahara K, Kawaishi M, et al. Detection of epidermal growth factor receptor mutations in serum as a predictor of the response to gefitinib in patients with non-small-cell lung cancer. Clin Cancer Res. 2006;12(13):3915-3921.

47. Horiike A, Kimura H, Nishio K, et al. Detection of epidermal growth factor receptor mutation in transbronchial needle aspirates of non-small cell lung cancer. Chest. 2007;131(6):1628-1634.

48. He C, Liu M, Zhou C, et al. Detection of epidermal growth factor receptor mutations in plasma by mutant-enriched PCR assay for prediction of the response to gefitinib in patients with non-small-cell lung cancer. Int J Cancer. 2009;125(10):2393-2399.

49. Bott M, Brevet M, Taylor BS, et al. The nuclear deubiquitinase BAP1 is commonly inactivated by somatic mutations and 3p21.1 losses in malignant pleural mesothelioma. Nat Genet. 2011;43(7):668-672.

50. Taniguchi K, Uchida J, Nishino K, et al. Quantitative detection of EGFR mutations in circulating tumor DNA derived from lung adenocarcinomas. Clin Cancer Res. 2011;17(24):7808-7815.

51. Maheswaran S, Sequist LV, Nagrath S, et al. Detection of mutations in EGFR in circulating lung-cancer cells. N Engl J Med. 2008;359(4): 366-377.

52. Yung TK, Chan KC, Mok TS, Tong J, To KF, Lo YM. Single-molecule detection of epidermal growth factor receptor mutations in plasma by microfluidics digital PCR in non-small cell lung cancer patients. Clin Cancer Res. 2009;15(6):2076-2084.

53. Oxnard GR, Paweletz CP, Kuang Y, et al. Noninvasive detection of response and resistance in EGFR-mutant lung cancer using quantitative next-generation genotyping of cell-free plasma DNA. Clin Cancer Res. 2014;20(6):1698-1705. 
54. Hu C, Liu X, Chen Y, et al. Direct serum and tissue assay for EGFR mutation in non-small cell lung cancer by high-resolution melting analysis. Oncol Rep. 2012;28(5):1815-1821.

55. Kim ST, Jung HY, Sung JS, et al. Can serum be used for analyzing the EGFR mutation status in patients with advanced non-small cell lung cancer? Am J Clin Oncol. 2013;36(1):57-63.

56. Jiang B, Liu F, Yang L, et al. Serum detection of epidermal growth factor receptor gene mutations using mutant-enriched sequencing in Chinese patients with advanced non-small cell lung cancer. J Int Med Res. 2011;39(4):1392-1401.

57. Bai H, Wang Z, Chen $\mathrm{K}$, et al. Influence of chemotherapy on EGFR mutation status among patients with non-small-cell lung cancer. J Clin Oncol. 2012;30(25):3077-3083.

58. Bai H, Mao L, Wang HS, et al. Epidermal growth factor receptor mutations in plasma DNA samples predict tumor response in Chinese patients with stages IIIB to IV non-small-cell lung cancer. J Clin Oncol. 2009;27(16):2653-2659.
59. Goto K, Ichinose Y, Ohe Y, et al. Epidermal growth factor receptor mutation status in circulating free DNA in serum: from IPASS, a phase III study of gefitinib or carboplatin/paclitaxel in non-small cell lung cancer. $J$ Thorac Oncol. 2012;7(1):115-121.

60. Yam I, Lam DC, Chan K, et al. EGFR array: uses in the detection of plasma EGFR mutations in non-small cell lung cancer patients. JThorac Oncol. 2012;7(7):1131-1140.

61. Zhao X, Han RB, Zhao J, et al. Comparison of epidermal growth factor receptor mutation statuses in tissue and plasma in stage I-IV non-small cell lung cancer patients. Respiration. 2013;85(2):119-125.

62. Weber B, Meldgaard P, Hager H, et al. Detection of EGFR mutations in plasma and biopsies from non-small cell lung cancer patients by allele-specific PCR assays. BMC Cancer. 2014;14:294.

63. Li Z, Zhang Y, Bao W, Jiang C. Insufficiency of peripheral blood as a substitute tissue for detecting EGFR mutations in lung cancer: a metaanalysis. Target Oncol. Epub March 14, 2014.

\section{Publish your work in this journal}

Lung Cancer: Targets and Therapy is an international, peer-reviewed, open access journal focusing on lung cancer research, identification of therapeutic targets and the optimal use of preventative and integrated treatment interventions to achieve improved outcomes, enhanced survival and quality of life for the cancer patient. Specific topics Cellular research and biomarkers; Identification of biotargets and agents with novel

Submit your manuscript here: http://www.dovepress.com/lung-cancer-targets--therapy-journa

\section{Dovepress}

mechanisms of action; Optimal clinical use of existing anticancer agents, including combination therapies; Radiation and surgery; Palliative care; Patient adherence, quality of life, satisfaction; Health economic evaluations. The manuscript management system is completely online and includes a very quick and fair peer-review system. Visit http://ww system. Visit http://www.dovepress.com/testimonials.php to read real quotes from published authors. 